\title{
The importance of achieving long-term treatment effects in ADHD
}

\author{
Pieter J. Hoekstra ${ }^{1}$ - Barbara J. van den Hoofdakker ${ }^{1}$. Annabeth P. Groenman ${ }^{1}$
}

Published online: 15 May 2021

(c) Springer-Verlag GmbH Germany, part of Springer Nature 2021

Over the past decade, there has been a strong increase in the number of children diagnosed with Attention-Deficit/ Hyperactivity Disorder (ADHD) [1]. The prescription rates of drugs to treat ADHD were between 47.3 and $59.6 \%$ in 2014-2015 [1]. Although pharmacological treatment of ADHD appears efficacious, treating children with medication has clear limitations. These include considerable rates of non-response [7], common adverse effects such as loss of sleep and appetite [9], and very limited information on longterm safety and efficacy. This emphasizes the importance of non-pharmacological treatment of ADHD. Studies into strategies to maintain initial results of non-pharmacological treatments are scarce, however. In the current issue, Qian and colleagues from the Peking University Sixth Hospital describe results of a second dose of ecological executive skills training for children with ADHD one year after an initial training. While the first dose of this executive skills training was mostly child-focused, the second dose (or booster) also included a behavior parent training component. Compared to a waiting list, the authors found that the booster intervention led to improvements on executive functioning (planning abilities and delay aversion) as measured by the Cambridge Neuropsychological Test Automated Battery, on daily executive functioning performance as measured by the BRIEF questionnaire, and on ratings of ADHD symptoms by parents. Improvements were maintained one year after the end of the booster training. Empirical evidence for a longterm behavioral treatment strategy for ADHD is important, given the chronic nature of ADHD.

Over the years, several meta-analyses have been performed on behavioral interventions for ADHD [10,11]. A recent meta-analysis [11] into the effects of socials skills training for children and adolescents with ADHD, covering 25 randomized trials with a total of 2690 participants,

Annabeth P. Groenman

a.groenman@accare.nl

1 Department of Child and Adolescent Psychiatry, University of Groningen, University Medical Center Groningen, Groningen, The Netherlands did not indicate statistically significant treatment effects on teacher-rated social skills, emotional competencies, or general behavior at the end of treatment, but found improvements on teacher-rated ADHD symptoms (standardized mean difference $[S M D]=0.26$ ). The authors, however, warned against a high risk of bias, lack of clinical significance, high heterogeneity, and low certainty regarding this finding. These disappointing findings are in line with the modest effects of social skills training in children with autism spectrum disorder (e.g., [6]). Organizational skills training appears to be a more promising intervention according to the results of another meta-analysis, covering 12 studies involving 1054 children with ADHD [2]. Both teachers and parents reported statistically significant improvements on symptoms of inattention. Teachers also reported better academic performance and average grade points.

Most behavioral interventions for children with ADHD have some component of parent training. Parent-mediated treatment works from the rationale that parents act as a therapist to modify the child's behavior. Following this rationale, parental behavior should change before the child's behavior can change [5]. Two meta-analyses on behavioral treatments, most of them with a parenting component $[4,10]$ will be discussed here. Both subdivide their outcomes in most proximal and probably blinded, to indicate whether the rater of the behavior was aware of the treatment allocation of the family. The meta-analysis by Daley et al. [4] focused on behavioral interventions for children and adolescents with ADHD, and not only examined child outcomes, but also included possible changes in parents. Meta-analytic evidence showed positive effects on proximally rated ADHD core symptoms $(S M D=0.35)$, symptoms of conduct disor$\operatorname{der}(S M D=0.26)$, social skills $(S M D=0.47)$, and academic achievement $(S M D=0.28)$. Importantly, Daley and colleagues also showed improvements on positive $(S M D=0.68)$ and negative parenting $(S M D=0.57)$, and parental self-concept $(S M D=0.37)$. Interestingly, also a small but significant effect of behavioral interventions for ADHD on parental mental health (Effect size $[E S]=0.09$ ) was found. Furthermore, they found that although probably blinded measures 
of ADHD $(S M D=0.02)$ did not reach significance, behavioral interventions did have a positive effect on probably blinded measures of conduct problems $(S M D=0.43)$, and positive $(S M D=0.63)$ and negative parenting $(S M D=0.43)$. The more recent meta-analysis of Rimestad and colleagues (2019) [10] focused solely on parent-mediated interventions in preschool children with ADHD, indicating positive effects of the interventions on proximally rated symptoms of ADHD $(E S=0.51)$ and conduct disorder $(E S=0.44)$ and on negative parenting $(E S=0.63)$.

The two meta-analyses discussed here show that behavioral interventions with a parent component not only improve the child's behavior, but also instigate behavioral changes in parents. However, they do not show whether these changes in parenting are necessary for behavioral changes in children even though several trials did show that changes in parental behaviors were predictive of child outcomes [3]. Also, the meta-analyses investigated effects of interventions directly post-treatment. Although there was no indication of improvement on probably blinded measures of ADHD, parent behaviors did appear to change. If a change in parenting behaviors is necessary to cause a change in child behavior, then this leaves open the possibility that directly posttreatment is too early to detect changes in core symptoms of ADHD by informants who are not involved in the treatment. This highlights the importance of including longer-term outcomes, as was done in the study of Qian and colleagues in this issue.

Both the meta-analysis by Daley and colleagues and by Rimestad and colleagues found high heterogeneity $\left(\mathrm{I}^{2}\right.$ between 45 and 87\%) among their effect sizes. High heterogeneity is found in nearly all meta-analyses regarding behavioral treatments for children and adolescents with ADHD and indicates that there is not a "one size fits all" solution. In aggregated data meta-analyses, a common method of identifying causes for heterogeneity is to exclude extreme effect sizes, perform subgroup analyses, or to perform a meta-regression. Although this approach usually resolves heterogeneity (i.e., reduces $\mathrm{I}^{2}$ ), it tells us little about the actual cause of this heterogeneity. For example, when performing meta-regression, one could add the percentage of medicated individuals as a predictor to a meta-regression and find higher effect sizes in studies where medication is allowed. This could lead to the conclusion that this intervention works better in medicated individuals. However, because one is working with aggregated data, i.e., means and standard deviations of the group, and not individual participant data, this foregoes the possibility that those with higher symptom severity are more likely to receive medication. Recently, we performed the first individual participant data meta-analysis (IPDMA) of behavioral interventions for children with ADHD [8], including the individual participant data of over 2200 children. IPDMA is a meta-analytic method that makes optimal use of all available data by including data at an individual level rather than at study level, which enables exploration of potential treatment moderators (e.g., age, sex, symptom severity, comorbidities of the child). Our IPDMA confirmed the short-term beneficial effects that behavioral interventions for children with ADHD have on ADHD and behavioral symptoms and impairments, as rated by informants most proximal to the treatments. More importantly, we were able to detect some subgroups of children who respond differently to behavioural interventions. We found that presence of a single parent family, higher ADHD symptom severity, higher conduct disorder symptom severity, and presence of a comorbid conduct disorder moderated treatment outcome. Interestingly, these moderators indicated worsening of symptoms in the control group. This constitutes a clear clinical message: some groups of children should not wait for behavioral treatment and be quickly treated to prevent deterioration of their symptoms.

In sum, there are several non-pharmacological treatment options for children with ADHD that are effective on the short-term. Very little meta-analytic evidence, however, is available on the long-term effects of treatments for ADHD. Typically, after the initial trial phase of randomized controlled trials, families are free to choose the treatment that they prefer (for obvious ethical reasons), making it difficult to draw strong conclusions about the long-term efficacy of behavioral treatments for ADHD. The study of Qian and colleagues in this issue is a laudable approach into establishing long-term effects of a non-pharmacological intervention for children with ADHD.

\section{References}

1. Anderson J (2018) Reported Diagnosis and Prescription Utilization Related to Attention Deficit Hyperactivity Disorder in Children Ages 5-17, 2008-2015. In Statistical Brief (Medical Expenditure Panel Survey (US)). Rockville (MD): Agency for Healthcare Research and Quality (US).

2. Bikic A, Reichow B, McCauley SA, Ibrahim K, Sukhodolsky DG (2017) Meta-analysis of organizational skills interventions for children and adolescents with attention-deficit/hyperactivity disorder. Clin Psychol Rev 52:108-123

3. Chronis-Tuscano A, O'Brien KA, Johnston C, Jones HA, Clarke TL, Raggi VL, Seymour KE (2011) The relation between maternal ADHD symptoms \& improvement in child behavior following brief behavioral parent training is mediated by change in negative parenting. J Abnorm Child Psychol 39(7):1047-1057. https://doi. org/10.1007/s10802-011-9518-2

4. Daley D, Van der Oord S, Ferrin M, Danckaerts M, Doepfner M, Cortese S, Group EAG (2014) Behavioral interventions in attention-deficit/hyperactivity disorder: a meta-analysis of randomized controlled trials across multiple outcome domains. J Am Acad Child Adolesc Psychiatry 53(8):835-847.e5. https://doi.org/ 10.1016/j.jaac.2014.05.013 
5. Daley D, Van Der Oord S, Ferrin M, Cortese S, Danckaerts M, Doepfner M, Sonuga-Barke EJ (2018) Practitioner review: current best practice in the use of parent training and other behavioural interventions in the treatment of children and adolescents with attention deficit hyperactivity disorder. J Child Psychol Psychiatry 59(9):932-947. https://doi.org/10.1111/jcpp.12825

6. Dekker V, Nauta MH, Timmerman ME, Mulder EJ, van der VeenMulders L, van den Hoofdakker BJ, de Bildt A (2019) Social skills group training in children with autism spectrum disorder: a randomized controlled trial. Eur Child Adolesc Psychiatry 28(3):415-424. https://doi.org/10.1007/s00787-018-1205-1

7. Graham J, Coghill D (2008) Adverse effects of pharmacotherapies for attention-deficit hyperactivity disorder. CNS Drugs 22:213237. https://doi.org/10.2165/00023210-200822030-00003

8. Groenman AP, Hornstra R, Hoekstra PJ, Steenhuis L, Aghebati A, Boyer BE, Buitelaar JK, Chronis-Tuscano A, Daley D, Dehkordian P, Dvorsky M, Franke N, DuPaul GJ, Gershy N, Harvey E, Hennig T, Herbert S, Langberg J, Mautone JA, Mikami AY, Pfiffner LJ, Power TJ, Reijneveld SA, Schramm SA, Schweitzer JB, Sibley MH, Sonuga-Barke E, Thompson C, Thompson M,
Webster-Stratton C, Xie Y, Luman M, van der Oord S, van den Hoofdakker BJ (2021) An individual participant data metaanalysis: behavioral treatments for children and adolescents with attention-deficit/hyperactivity disorder. J Am Acad Child Adolesc Psychiatry 28:S0890-8567(21)00233-1 https://doi.org/10.1016/j. jaac.2021.02.024

9. Groenman AP, Schweren LJ, Dietrich A, Hoekstra PJ (2017) An update on the safety of psychostimulants for the treatment of attention-deficit/hyperactivity disorder. Expert Opin Drug Saf 16(4):455-464. https://doi.org/10.1080/14740338.2017.1301928

10. Rimestad ML, Lambek R, Zacher Christiansen H, Hougaard E (2016) Short-and long-term effects of parent training for preschool children with or at risk of ADHD: a systematic review and metaanalysis. J Attention Disord 23(5):423-434. https://doi.org/10. $1177 / 1087054716648775$

11. Storebø OJ, Elmose Andersen M, Skoog M, Joost Hansen S, Simonsen E, Pedersen N, Gluud C (2019) Social skills training for attention deficit hyperactivity disorder (ADHD) in children aged 5 to 18 years. Cochrane Database Syst Rev 6(6):Cd008223. https://doi.org/10.1002/14651858.CD008223.pub3 